\title{
Comentário a \\ “CIÊNCIA E ÉTICA EM POPPER: A ÉTICA DA RESPONSABILIDADE DOS CIENTISTAS"
}

Amélia de Jesus Oliveira ${ }^{1}$

Referência do artigo comentado: Dias, E. A. Ciência e ética em Popper: a ética da responsabilidade dos cientistas. Trans/Form/Açáo: Revista de Filosofia da Unesp, v. 44, n. 3, p. 81-100, 2021.

A discussão promovida por Elizabeth Dias (2021) fomenta desdobramentos interpretativos com relação à gênese e percurso da obra de Popper, com foco na ética. No que segue, apresento algumas consideraçóes, suscitadas pela leitura do artigo. Para começar, gostaria de lembrar que o título da primeira obra de Popper, Os dois problemas fundamentais da teoria do conhecimento, "é uma alusão" ao título da primeira obra de Schopenhauer, Os dois problemas fundamentais da ética (POPPER, 1978, p. xvii; 1974 , p. 65-66). E, se Popper se mostrou um crítico da soluçâo proposta por Schopenhauer ao problema da liberdade e da fundamentação da moral (os dois problemas fundamentais da ética) (POPPER, 1968, p. 184-200), ele não perdeu oportunidade de valorizar, em seus escritos, a obra schopenhaueriana como uma teoria da ética (POPPER, 1974, p. 154); como exemplo de uma ética "simples, direta e clara" (POPPER, 2000, p. 189); como referência de

${ }^{1}$ Professora de Filosofia na Faculdade João Paulo II (FAJOPA), Marília. SP - Brasil. (DD https://orcid. org/0000-0003-0905-9079. E-mail: amelijeso@gmail.com.

https://doi.org/10.1590/0101-3173.2021.v44n3.07.p101

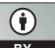


escrita. ${ }^{2}$ A análise desse aspecto, na obra de Schopenhauer, alude ao segundo compromisso elencado por Popper (1994, p. 123), baseado no juramento de Hipócrates: a inserção em uma tradição de debate, de crítica a combater o estilo obscuro.

Quando propõe uma "nova ética profissional", em "Tolerância e responsabilidade intelectual”, Popper (2000) destaca a clareza e a simplicidade da ética de Schopenhauer. Quando discute ideias progressistas na arte, Popper (1974, p. 56) cita o que entende ser uma das mais "sábias consideraçôes de Schopenhauer", a de que "[...] em toda arte [...] a simplicidade é essencial [...] no mínimo, é sempre perigoso negligenciá-la.” Trata-se, uma vez mais, da valorização da simplicidade em face de modismos que desconsideram a tradiçáa. ${ }^{3}$ Assim, se o primeiro livro de Popper sobre ciência foi inspirado no título do livro sobre os dois problemas fundamentais da ética, é também verdade que Schopenhauer, um filósofo que se opôs "genuinamente ao irracionalismo" (POPPER, 1968, p. 200), continuou sendo uma referência para a discussão sobre ciência e ética.

O propósito de Dias (2021) de mostrar que a concepção popperiana de ciência está alicerçada em uma ética da responsabilidade, já esboçada nos primeiros escritos de Popper, amplia o enfoque sobre as raízes éticas em todo o pensamento popperiano, conforme defendido pelos intérpretes por ela mencionados, como, por exemplo, Kiesewetter (1997) e Artigas (1998). Ao discutir os valores e as consequências do critério de falsificabilidade, composto de regras lógicas e metodológicas, a autora lembra as críticas de Popper a outras visôes de ciência, como a do positivismo lógico e a do convencionalismo.

E isso me incitou a refletir sobre a atitude de Popper em relação a essas escolas que critica. Os leitores popperianos, focados em compreender sua proposta de demarcação para ciência, estão habituados às suas reiteradas e, às vezes, duras críticas aos representantes dessas escolas. ${ }^{4}$ É possível, no entanto,

${ }^{2}$ Para Popper (1968, p. 200), o "[...] esforço [de Schopenhauer] para ser compreendido tornou-o um dos poucos grandes mestres da lígua alemã.” No prefácio à edição alemã de $O s$ dois problemas fundamentais da teoria do conhecimento, Popper (1978, p. xviii) declara que Schopenhauer e Bertrand Russell foram e continuavam sendo seus modelos inatingíveis de escrita em estilo claro.

3 Schopenhauer ainda é referência, quando Popper discute simplicidade e grau de falsificabilidade (1961, p. 141, n.1). Limito-me aqui a comentar algumas das passagens da obra de Popper em que ele se refere a Schopenhauer. É importante lembrar que $A$ sociedade aberta e seus inimigos (POPPER, 2002) é uma fonte rica para esse propósito, sobretudo pelo reconhecimento da honestidade intelectual schopenhaueriana.

${ }^{4}$ Vale assinalar que Popper assumiu a culpa pela morte do positivismo lógico (POPPER, 1974, p. 69) e associou o convencionalismo de Poincaré e Duhem ao instrumentalismo, também alvo de sua crítica 
verificar passagens da obra de Popper em que se revelou em sintonia com seus representantes. No prefácio à primeira edição inglesa de $A$ lógica da pesquisa científica, Duhem e Poincaré são mencionados, entre outros pensadores, duas vezes, como representantes de uma tradição que valorizou e esteve empenhada em aumentar o conhecimento científico, como frisa Popper (1961, p. 23), contra "uma especialização estreita" e a "fé obscurantista na habilidade especial do técnico e em seu conhecimento e autoridades pessoais", identificados em seu tempo.

Duhem e Poincaré são autores citados por Popper, em diversas passagens de sua obra, algumas vezes para corroboração de algumas de suas consideraçóes. E, embora o tratamento mais direto dado a esses pensadores os relacione à caracterização que Popper ofereceu da escola convencionalista, em uma crítica bastante apropriada para seus propósitos, é possível notar a importância deles na formação e explicitação da visão de ciência popperiana, enquanto pensadores que estiveram preocupados em refletir sobre o valor e o objetivo do conhecimento científico. Em "O significado atual de dois argumentos de Henri Poincaré", Popper (1981) se refere a Poincaré, como "o maior de todos os filósofos da ciência" e remete o leitor à introdução de $O$ valor da ciência (La valeur de la science), de Poincaré, como uma fonte em prol de suas próprias ideias acerca da meta da ciência.

No texto indicado, Poincaré argumenta em prol da incessante perseguição da verdade, sobre a impossibilidade de separação da verdade científica da verdade moral, sobre a realidade objetiva e sujeito cognoscente, entre outros aspectos, a fim de afirmar que a ciência tem um valor que extrapola as finalidades práticas.

Duhem (1989), em "O valor da teoria física" (La valeur de la théorie physique), um texto publicado originalmente em 1908, defendeu também que o valor da ciência vai além de sua utilidade prática e produz conhecimento sobre o mundo.

As abordagens de Poincaré e Duhem sobre o valor e a meta da ciência foram fonte para Popper do que ele chamou de tradição racionalista, uma tradição que era valorizada por suas realizaçóes práticas, mas principalmente pelo conteúdo informativo, por sua influência libertadora (POPPER, 1968, p. 101-102).

(POPPER,1968, 104). A caracterização que Popper ofereceu da escola convencionalista, ainda que útil à sua argumentação, resultou, entretanto, questionável. Ver Hacohen (2002) e Oliveira (2012). 
Sem espaço para discutir de modo mais detalhado semelhanças entre a posição de Popper em relação a Poincaré e Duhem, quero ressaltar que os três princípios éticos salientados por Popper, em "Tolerância e responsabilidade intelectual", e discutidos por Elizabeth Dias (2021) - a saber, a falibilidade, a discussão racional e a aproximação da verdade - encontram campos de análise na epistemologia desses autores "convencionalistas". 5

$\mathrm{Na}$ tradição racional, Duhem e Poincaré foram, entre outros pensadores, importantes fontes para a concepção do Círculo de Viena, conforme se pode verificar no panfleto de $1929 .{ }^{6}$ E Popper, que foi um tanto crítico e um tanto aliado dos convencionalistas, foi também crítico e aliado dos positivistas lógicos, pela atitude racional, conforme podemos constatar em seus escritos.

Em $O$ mito do contexto, relata Popper (1994, p. 67): "Devido à atitude tolerante adotada por alguns membros do círculo de Viena, o meu livro Logik der Forschung, no qual criticava este círculo positivista [...] foi publicado em uma série de livros editados por Moritz Schlick e Philipp Frank."7 A atitude de tolerância, correspondente à honestidade intelectual, à admissão de nossa falibilidade, sem fanatismos, é viabilizadora da discussão racional e, segundo Popper, foi característica marcante do Círculo de Viena. Em sua autobiografia, ele se refere a essa instituição como admirável; lamenta seu desaparecimento como "uma perda muito séria"; discorre sobre a reivindicaçáo de Carnap por "racionalidade, por maior responsabilidade intelectual" e declara que é pela atitude geral de esclarecimento, pela concepção crítica da filosofia que se sente unido ao Círculo e a Bertrand Russell (POPPER, 1974, p. 70).

Com estas breves consideraçóes, suscitadas pelo artigo de Elizabeth Dias (2021), gostaria de acentuar sua defesa (e dos autores que comenta) de que o pensamento popperiano tem raízes éticas e que, a todo tempo, ainda que em graus distintos, Popper deu indícios disso. Como um estudante interessado em problemas da filosofia e da ciência, ele questionou seus mestres e ousou propor soluçóes que acreditou renovadas para o avanço do conhecimento. Concordemos ou não com todas suas conclusôes, é certo que o debate por ele empreendido lança luzes quando nos voltamos a analisar o passado da filosofia. Depois de algumas décadas, é sempre necessário, por exemplo, como recomenda Thomas Nickles (1995, p 149-150), “[...]

5 Ver Oliveira (2005), especialmente p. 119-128.

${ }^{6}$ A concepção científica do mundo - o Círculo de Viena, de Hans Hahn, Otto Neurath e Rudolf Carnap. Cadernos de História e Filosofia da Ciência, v. 10, p. 5-20, 1986.

${ }^{7}$ A atitude tolerante de Schlick e Frank é lembrada ainda em Popper (2000, p. 89). 
considerar os positivistas em seus próprios problemas e contextos culturais. Afinal, em alguns desses contextos, adotar uma atitude em relação à ciência e aos cientistas era assumir uma atitude moral e política que era corajosa e progressiva." E Popper reconheceu e registrou isso. Seus escritos ressaltam e promovem a atitude corajosa e progressiva dos defensores do valor da filosofia e da ciência, de discussão racional, de tolerância, de honestidade intelectual, de uma ética da responsabilidade contra o obscurantismo e o irracionalismo. Refletir sobre esses temas, tão caros e imbricados na filosofia popperiana, é oportuno e urgente em tempos tấo sombrios e tão necessitados de buscas por um mundo melhor.

\section{REFERÊNCIAS}

ARTIGAS, M. Lógica y ética en Karl Popper. Pamplona: EUNSA, 1998.

DIAS, E. A. Ciência e ética em Popper: a ética da responsabilidade dos cientistas. Trans/ Form/Açáo: revista de filosofia da Unesp, v. 44, n. 3, p. 81-100, 2021.

DUHEM, P. La valeur de la théorie physique. In: DUHEM, P. La théorie physique, son objet, sa structure. Paris: Vrin, 1989. p. 473-509.

HACOHEN. M. H. Karl Popper - The Formative Years, 1902-1945. Cambridge: Cambridge, University Press, 2002.

HAHN, H.; NEURATH, O.; CARNAP, R. A concepção científica do mundo - o Círculo de Viena. Cadernos de História e Filosofia da Ciência, v. 10, p. 5-20, 1986.

KIESEWETTER, H. Fundamentos éticos da filosofia de Popper. In: O’ HEAR, A. (org.). Karl Popper: filosofia e problemas. São Paulo: Editora da Unesp, 1997, p. 325-340.

NICKLES, T. Philosophy of Science and History of Science. Osiris, 2. Series, v. 10, p. 138-163, 1995.

OLIVEIRA, A. J. Popper e o convencionalismo. 2005. Dissertação (Mestrado em Filosofia) - Faculdade de Filosofia e Ciências, Universidade Estadual Paulista "Júlio de Mesquita Filho", Marília, 2005.

POINCARÉ, H. La valeur de la science. Paris: Flammarion, 1970.

POPPER, K. R. The Logic of Scientific Discovery. New York: Science, 1961.

POPPER, K. R. Conjectures and Refutations. The Growth of Scientific Knowledge. New York: Harper \& Row, 1968.

POPPER, K. R. Autobiography of Karl Popper. In: SCHILPP, P. A. The Philosophy of Karl Popper. La Salle, Illinois: Open Court, 1974. 
POPPER, K. R. The Two Fundamental Problems of the Theory of Knowledge. London and New York: Routledge, 1978.

POPPER, K. R. La signification actuelle de deux arguments d'Henri Poincaré. In: BOUVERESSE, R. Karl Popper ou le rationalisme critique. Paris: Vrin, 1981. p. 191 195.

POPPER, K. R. The Myth of the Framework. London: Routledge, 1994.

POPPER, K. R. In Search of a Better World. London: Routledge, 2000.

POPPER, K. R. The Open Society and its Enemies. Princeton: Princeton University Press, 2002. 